\title{
Cerebral Astrocytoma
}

National Cancer Institute

\section{Source}

National Cancer Institute. Cerebral Astrocytoma. NCI Thesaurus. Code C4951.

An astrocytoma that arises from the cerebral hemispheres. 